\title{
Who is eating where? Findings from the SocioEconomic Status and Activity in Women (SESAW) study
}

\author{
Lukar E Thornton*, David A Crawford and Kylie Ball
}

Centre for Physical Activity and Nutrition Research, School of Exercise and Nutrition Sciences, Deakin University, 221 Burwood Highway, Burwood, Victoria 3125, Australia

Submitted 7 March 2010: Accepted 16 September 2010: First published online 10 December 2010

\begin{abstract}
Objective: Foods prepared outside of the home have been linked to less-than-ideal nutrient profiles for health. We examine whether the locations where meals are prepared and consumed are associated with socio-economic predictors among women.

Design: A cross-sectional study using self-reported data. We examined multiple locations where meals are prepared and consumed: (i) at home; (ii) fast food eaten at home; (iii) fast food eaten at the restaurant; (iv) total fast food; (v) non-fast-food restaurant meals eaten at home; (vi) non-fast-food restaurant meals eaten at the restaurant; and (vii) all non-fast-food restaurant meals. Multilevel logistic regression was used to determine whether frequent consumption of meals from these sources varied by level of education, occupation, household income and area-level disadvantage. Setting: Metropolitan Melbourne, Australia.

Subjects: A total of 1328 women from forty-five neighbourhoods randomly sampled for the SocioEconomic Status and Activity in Women study.

Results: Those with higher educational qualifications or who were not in the workforce (compared with those in professional employment) were more likely to report frequent consumption of meals prepared and consumed at home. High individualand area-level socio-economic characteristics were associated with a lower likelihood of frequent consumption of fast food and a higher likelihood of frequent consumption of meals from non-fast-food sources. The strength and significance of relationships varied by place of consumption.

Conclusions: The source of meal preparation and consumption varied by socioeconomic predictors. This has implications for policy makers who need to continue to campaign to make healthy alternatives available in out-of-home food sources.
\end{abstract}

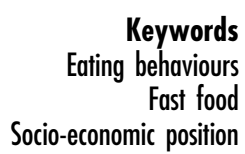

Over $60 \%$ of Australian adults and $25 \%$ of children are now overweight or obese ${ }^{(1)}$ and therefore at increased risk for multiple adverse health outcomes, including type 2 diabetes, CVD, high blood pressure, high cholesterol, asthma, arthritis and some cancers ${ }^{(2,3)}$. Consumption of energy-dense foods and beverages is a key modifiable risk factor for weight gain and obesity ${ }^{(4,5)}$.

Fast-food outlets are one of the most recognisable sources of energy-dense foods, despite some outlets offering a limited range of healthy options. In Britain, the energy density of traditional fast-food menus is reported to be up to $65 \%$ higher than that of the average British diet and more than twice as high as that recommended for a healthy diet ${ }^{(6)}$. Although it is recognised that energydense meals can also be obtained from sources other than fast-food outlets, there is little consistent information available on the nutritional quality of meals from nonfast-food restaurants, although it has been suggested that foods from full-service restaurants may be equally healthy or even unhealthier than some fast-food options ${ }^{(7)}$. Compared with meals prepared at home, and acknowledging that meals from all sources are likely to be highly variable in nutritional quality depending on the ingredients and cooking methods, research has shown that food prepared outside of home (FPOH) contribute more energy per eating occasion and that eating $\mathrm{FPOH}$ more often results in a higher proportion of total energy in the form of fat and saturated fat and lower intakes of dietary fibre, $\mathrm{Ca}$ and $\mathrm{Fe}^{(8,9)}$.

In recent decades, the eating patterns of the population in a number of developed countries have been characterised by declines in consumption of meals prepared at home and increases in consumption of $\mathrm{FPOH}^{(8-13)}$. For example, US data indicate that, for all Americans over the age of 18 years, the percentage of total energy obtained from restaurants or fast-food outlets increased significantly from $8 \%$ in $1977-1978$ to $22 \%$ in $1994-1996^{(9)}$. In Australia, 24 h dietary recall data collected in 1996 revealed that, on average, 
$12 \cdot 9 \%$ of daily energy was sourced from $\mathrm{FPOH}$ among women and $13.5 \%$ among men ${ }^{(14)}$. Among those who had consumed $\mathrm{FPOH}$, the contribution of these sources to daily energy intake was over $36 \%{ }^{(14)}$.

Consequently, the increased sourcing of meals from outside the home is recognised by WHO and others as a potential contributor to increases in adverse health outcomes such as weight gain and metabolic outcomes ${ }^{(15-17)}$. Specifically, studies have revealed that a higher consumption of, or expenditure on, FPOH is associated with less-healthy nutritional profiles in Westernised countries such as Australia ${ }^{(14)}$, the USA ${ }^{(8,9,18)}$ and countries within Europe ${ }^{(19,20)}$.

Although increased socio-economic disadvantage has been linked to lower dietary quality ${ }^{(21-23)}$, and specifically to increased fast-food consumption ${ }^{(22,24-26)}$, less is known about predictors of more general out-of-home purchasing $^{(14,20)}$ or of consumption of meals prepared at home. In addition, it is rare for studies examining predictors of eating behaviour to consider multiple places of consumption, or multiple indicators of socio-economic position. Consideration of multiple socio-economic indicators is important, as each of these can independently contribute to eating behaviours ${ }^{(27,28)}$.

We use data from the SocioEconomic Status and Activity in Women (SESAW) study to add to the limited evidence on the individual- and area-level socio-economic determinants of eating behaviours. We investigated whether various socio-economic factors were associated with the consumption of meals prepared at home or from away-from-home sources (fast-food restaurants and non-fast-food restaurants). These sources are likely to differ substantially with regard to nutritional quality, with foods prepared at home more often likely to be healthier than FPOH. Further, for $\mathrm{FPOH}$, we investigated differences with regard to the place where meals were consumed, as these may be differently associated with socio-economic characteristics. It is also plausible that place of consumption is important from a nutrition point of view because consuming meals within a restaurant means that there is greater potential for overconsumption; for instance, when extra soft drinks are ordered (or unlimited soft drinks are available, as occurs in some fast-food outlets), or when impulsive purchases such as desserts are made at the end of the meal. We therefore hypothesise that each of the sources examined is differently associated with socio-economic characteristics. Identification of factors associated with sources of meals may provide an avenue for public health interventions that seek to improve eating behaviours.

\section{Methods}

\section{Participants}

These analyses are based on data from 1328 women participating in the SESAW study. The study methods have been described in detail previously ${ }^{(29,30)}$. Briefly, women were recruited from the Australian electoral roll (voting is compulsory for all Australian adults) using a stratified random sampling procedure from forty-five neighbourhoods (suburbs) of different levels of disadvantage in Melbourne, Australia. On the basis of the 2001 Census data, the Australian Bureau of Statistics assigned suburbs a SEIFA (Socioeconomic Index for Areas) Index of Relative Socioeconomic Disadvantage (IRSD) score $^{(31)}$. All suburbs within $30 \mathrm{~km}$ of the Melbourne central business district were ranked according to the SEIFA score, and fifteen suburbs were drawn randomly from each of the lowest, middle and highest SEIFA septiles. Given the differential response rates of the socioeconomic status (SES) groups observed in other mailbased health surveys, we oversampled from the low- and mid-SES neighbourhoods, relative to the high-SES neighbourhood, by a ratio of $1: 1 \cdot 2: 1 \cdot 5$. The suburbs sampled had an average population size of 11717 people (range: 2729-45 509) and an average geographic size of $6 \cdot 34 \mathrm{~km}^{2}$ (range: $0 \cdot 89-30 \cdot 2$ ).

In 2004, 2400 women aged 18-65 years were posted a survey assessing dietary behaviours and their determinants. A total of 1136 women responded (50\% response, excluding from the denominator 127 women whose surveys were returned to the sender unopened and therefore could not be contacted by mail). A second independent sample that was mutually exclusive of participants from the first sample was drawn in the same manner for a separate physical activity survey. All participants completing that survey were asked whether they were willing to complete a further survey, and those agreeing were posted the dietary survey. Initial surveys were posted in March 2004 and the second phase was initiated roughly between April and June depending on the response of the original survey. This second phase resulted in an additional 444 diet surveys ( $42 \%$ of those completing the original physical activity survey and 19\% of all women contacted for the physical activity survey). Excluding data from thirteen women who had moved/ were ineligible, and 168 women who had missing data on one or more of the individual-level study variables, the final sample size was 1328.

\section{Outcome measures}

Respondents were asked about the number of meals (including breakfast, lunch and dinner) per week they ate that were: (i) prepared/cooked and eaten at home; (ii) from fast-food restaurants (e.g. pizza, McDonalds) eaten as takeaway at home/work/study (including home delivery); (iii) from fast-food restaurants eaten within the restaurant; (iv) from non-fast-food restaurants (e.g. Chinese, Indian) eaten at home/work/study; and (v) from a non-fast-food restaurant/café eaten at the restaurant/café (not at work/ study). Six response categories were listed, ranging from 'never' to 'six to seven or more meals per week'. Total consumption of either fast-food or non-fast-food restaurant 
meals was determined by tallying the frequency of consumption of these as takeaway and within the restaurant. All outcomes were recoded to binary variables labelled infrequent and frequent, with frequent consumption defined as six or more meals per week for those prepared/ cooked and eaten at home and one or more meals per week for each of the FPOH sources. Those who consumed meals from these sources less frequently than this were categorised as infrequent.

\section{Socio-economic measures}

We considered a number of socio-economic predictors: highest education level attained (higher degree or degree; trade, certificate or Year 12; less than Year 12), current occupation (professional, white collar, blue collar, not in workforce), total annual gross household income (in \$AUS: $\geq 78000$; 52 000-77999; 37000-51999; $\leq 36999$; missing) and tertiles of neighbourhood socio-economic disadvantage (as defined by the SEIFA IRSD) score defined above. We included multiple socio-economic predictors, as each has the potential to make an independent contribution to food choice ${ }^{(27,28)}$.

\section{Potential confounders}

We adjusted for a number of potential confounders that included age, country of birth (Australia; overseas), marital status (married/de facto; separated/divorced/ never married/widow), presence of children aged $\leq 18$ years in the household (yes/no) and number of people dependent on the household income.

\section{Statistical analyses}

Descriptive and multilevel analyses were undertaken in 2009 using the STATA statistical software package version $10 \cdot 1$ (StataCorp., College Station, TX, USA). Crosstabs with Pearson's $\chi^{2}$ tests were applied for the bivariate analyses. We then undertook multilevel binary logistic regression using maximum likelihood estimation for each outcome, adjusting for the clustering of individuals within suburbs and covariates. Models are adjusted for confounders and each model contains a separate set of potential confounders based on an a priori conceptualisation ${ }^{(32)}$ of these using existing literature $^{(27,28)}$. This was done to avoid overadjustment, which can occur when all covariates are included in models, even though they may not fit along the causal pathway ${ }^{(33)}$. Relationships were considered significant when the $P$ value was $\leq 0.05$ according to a two-tailed test of significance.

\section{Results}

\section{Descriptive and bivariate}

The demographic and socio-economic characteristics of the 1328 participants are shown in Table 1. The proportion of the sample consuming food from each of the meal sources on a frequent basis is also reported. Frequently eating meals at home was less popular among those who were not married, lived in households without children, had Year 12 or equivalent educational qualifications, and among both blue- and white-collar employees. Frequently eating meals at a fast-food outlet was less common among those who were married, lived in households without children, had higher education, were in professional employment, had higher incomes or lived in high-SES areas; a greater proportion of these people frequently ate meals from non-fast-food restaurants irrespective of the place of consumption.

\section{Multilevel analysis}

\section{Meals prepared and eaten at home}

In models adjusted for potential confounders, preparing and consuming six or more meals per week at home was less likely among those with lower educational attainments compared with those with a bachelor's degree or higher (Table 2). Compared with those in professional employment, those not in the workforce were almost $50 \%$ more likely to frequently eat meals prepared at home. No association was found for income- and area-level SES.

\section{Fast-food restaurant meals}

Compared with those with a bachelor's degree or higher, eating within a fast-food restaurant on a weekly basis was over $60 \%$ more likely among those with Year 12, trade or certificate qualifications and over twice as likely for those with less than Year 12 level educational attainment. No association was found between education and total fastfood meals or eating as takeaway.

Being a blue-collar employee increased the likelihood of consuming fast food (irrespective of the place of consumption) by more than twofold compared with professional employees. Compared with those with an annual household income of $\geq \$$ AUS 78000 , those in the middle two income groups were around two-and-a-half times more likely to eat within fast-food restaurants. No significant associations were found between income and fastfood meals eaten at home or total fast-food consumption. Compared with those in high-SES areas, frequent total consumption of fast-food meals and consumption of fastfood meals at home only were more likely among those in both mid- and low-SES neighbourhoods, whereas frequently eating within a fast-food outlet was more likely only among low-SES residents.

\section{Non-fast-food restaurant meals}

Significant trends were reported for education and nonfast-food restaurant meal consumption, with those with lower educational attainment less likely to consume a meal from this source on a weekly basis. Blue-collar employees were only half as likely as professional employees to frequently consume a meal within a nonfast-food restaurant. Weekly consumption of meals from 
Table 1 Demographic and socio-economic characteristics of the sample population by meal source

\begin{tabular}{|c|c|c|c|c|c|c|c|c|c|}
\hline & \multirow{2}{*}{$\begin{array}{c}\text { Total } \\
n \\
\end{array}$} & $\begin{array}{c}\text { Meals prepared } \\
\text { and eaten at } \\
\text { home } \\
(\geq 6 / \text { week })\end{array}$ & $\begin{array}{l}\text { Fast food } \\
\text { (at home) } \\
(\geq 1 / \text { week) }\end{array}$ & $\begin{array}{c}\text { Fast food } \\
\text { (in restaurant) } \\
(\geq 1 / \text { week) }\end{array}$ & $\begin{array}{l}\text { Fast food (total) } \\
\quad(\geq 1 / \text { week })\end{array}$ & $\begin{array}{l}\text { Non-fast-food } \\
\text { restaurant } \\
\text { (at home) } \\
(\geq 1 / \text { week })\end{array}$ & $\begin{array}{c}\text { Non-fast-food } \\
\text { restaurant } \\
\text { (in restaurant) } \\
(\geq 1 / \text { week) }\end{array}$ & \multicolumn{2}{|c|}{$\begin{array}{l}\text { Non-fast-food } \\
\text { restaurant (total) } \\
(\geq 1 / \text { week })\end{array}$} \\
\hline & & $\%$ & $\%$ & $\%$ & $\%$ & $\%$ & $\%$ & $n$ & $\%$ \\
\hline \multirow[t]{2}{*}{ Total } & 1328 & $75 \cdot 2$ & $21 \cdot 5$ & $14 \cdot 2$ & $26 \cdot 3$ & $20 \cdot 3$ & $27 \cdot 6$ & 391 & $37 \cdot 3$ \\
\hline & Median IQR & Median & Median & Median & Median & Median & Median & Median & IQR \\
\hline Age (years) & $31-50$ & $32-52$ & $26-44$ & $26-45$ & $26-45$ & $27-44$ & $29-49$ & 38 & $29-48$ \\
\hline Number of household members & $2-4$ & $2-4$ & $2-4$ & $2-4$ & $2-4$ & $2-4$ & $2-3$ & 2 & $2-4$ \\
\hline & $\%$ & $\%$ & $\%$ & $\%$ & $\%$ & $\%$ & $\%$ & \multicolumn{2}{|c|}{$\%$} \\
\hline \multicolumn{10}{|l|}{ Country of birth } \\
\hline Australia (n 1030) & \multirow{2}{*}{$\begin{array}{l}77 \cdot 6 \\
22 \cdot 4\end{array}$} & $74 \cdot 7$ & \multirow{2}{*}{$22 \cdot 3$} & \multirow{2}{*}{$\begin{array}{l}14 \cdot 1 \\
14 \cdot 8\end{array}$} & \multirow{2}{*}{$\begin{array}{l}27 \cdot 8 \\
21 \cdot 1^{*}\end{array}$} & \multirow{2}{*}{$\begin{array}{l}20 \cdot 3 \\
20 \cdot 5\end{array}$} & \multirow{2}{*}{$\begin{array}{l}28 \cdot 4 \\
25 \cdot 2\end{array}$} & \multirow{2}{*}{\multicolumn{2}{|c|}{$\begin{array}{l}38 \cdot 0 \\
34 \cdot 9\end{array}$}} \\
\hline Overseas (n 298) & & $77 \cdot 2$ & & & & & & & \\
\hline Marital status & & & & & & & & & \\
\hline Married/de facto ( $n$ 857) & $64 \cdot 5$ & $80 \cdot 8$ & $18 \cdot 9$ & $12 \cdot 4$ & $23 \cdot 3$ & $18 \cdot 8$ & $25 \cdot 8$ & & $5 \cdot 2$ \\
\hline $\begin{array}{l}\text { Separated/divorced/never married/widow } \\
\text { (n 471) }\end{array}$ & $35 \cdot 5$ & $65 \cdot 2^{\star \star \star}$ & $26 \cdot 1^{\star *}$ & $17 \cdot 6^{\star \star}$ & $31 \cdot 6^{\star \star \star}$ & $23 \cdot 1$ & $31 \cdot 0^{*}$ & & $0 \cdot 1^{*}$ \\
\hline Children aged $\leq 18$ years in the household & & & & & & & & & \\
\hline No $(n 783)$ & $59 \cdot 0$ & $72 \cdot 8$ & $18 \cdot 8$ & $11 \cdot 8$ & $22 \cdot 9$ & $21 \cdot 1$ & $33 \cdot 0$ & & $1 \cdot 9$ \\
\hline Yes, one or more children $(n 545)$ & $41 \cdot 0$ & $78 \cdot 7^{*}$ & $25 \cdot 3^{\star \star}$ & $17 \cdot 8^{\star \star}$ & $31 \cdot 2^{\star \star *}$ & $19 \cdot 3$ & $20 \cdot 0^{\star * *}$ & & $0 \cdot 6^{* \star *}$ \\
\hline Education & & & & & & & & & \\
\hline Degree or higher degree $(n 508)$ & $38 \cdot 3$ & $80 \cdot 1$ & $22 \cdot 2$ & $10 \cdot 8$ & $26 \cdot 0$ & $27 \cdot 4$ & $37 \cdot 0$ & & $8 \cdot 6$ \\
\hline Year 12 , trade or certificate $(n 531)$ & $40 \cdot 0$ & $70 \cdot 2$ & $22 \cdot 2$ & $17 \cdot 3$ & $28 \cdot 1$ & $18 \cdot 6$ & $24 \cdot 1$ & & $4 \cdot 5$ \\
\hline Less than Year 12 ( $n$ 289) & $21 \cdot 8$ & $75 \cdot 8^{\star \star *}$ & $18 \cdot 7$ & $14 \cdot 5^{\star}$ & 23.5 & $11 \cdot 1^{\star * *}$ & $17 \cdot 7^{\star \star \star}$ & & $2 \cdot 5^{\star \star \star}$ \\
\hline Occupation & & & & & & & & & \\
\hline Professional ( $n$ 574) & $43 \cdot 2$ & $77 \cdot 4$ & $18 \cdot 8$ & $10 \cdot 3$ & $22 \cdot 8$ & $24 \cdot 2$ & $34 \cdot 5$ & & $5 \cdot 8$ \\
\hline White collar ( $n$ 320) & $24 \cdot 1$ & $68 \cdot 8$ & $21 \cdot 2$ & $14 \cdot 4$ & $26 \cdot 6$ & $19 \cdot 4$ & $26 \cdot 6$ & & 5.9 \\
\hline Blue collar ( $n$ 116) & $8 \cdot 7$ & $71 \cdot 6$ & $32 \cdot 8$ & $25 \cdot 0$ & $38 \cdot 8$ & $21 \cdot 6$ & $14 \cdot 7$ & & $5 \cdot 9$ \\
\hline Not in workforce $(n$ 318) & $24 \cdot 0$ & $79 \cdot 3^{\star \star}$ & $21 \cdot 7^{*}$ & $17 \cdot 3^{\star \star *}$ & $27 \cdot 7^{\star \star}$ & $13 \cdot 8^{* *}$ & $21 \cdot 1^{\star \star \star}$ & & $7 \cdot 4^{\star \star \star}$ \\
\hline Income (\$AUS) & & & & & & & & & \\
\hline$\geq 78000(n 321)$ & $24 \cdot 2$ & $83 \cdot 5$ & $20 \cdot 3$ & $7 \cdot 5$ & $23 \cdot 1$ & $25 \cdot 6$ & $37 \cdot 7$ & & 8.9 \\
\hline $52000-77999(n$ 191) & $14 \cdot 4$ & $74 \cdot 4$ & $28 \cdot 8$ & $18 \cdot 9$ & $32 \cdot 5$ & $25 \cdot 1$ & $28 \cdot 3$ & & $9 \cdot 8$ \\
\hline $37000-51999(n 156)$ & $11 \cdot 8$ & $73 \cdot 1$ & $23 \cdot 7$ & $21 \cdot 2$ & $31 \cdot 4$ & $19 \cdot 2$ & $23 \cdot 7$ & & 5.9 \\
\hline$\leq 36999(n 158)$ & $11 \cdot 9$ & $79 \cdot 1$ & $18 \cdot 4$ & $16 \cdot 5$ & $26 \cdot 6$ & $13 \cdot 9$ & $13 \cdot 9$ & & $1 \cdot 5$ \\
\hline Missing (n 502) & $37 \cdot 8$ & $69 \cdot 7^{\star \star \star}$ & $19 \cdot 7$ & $13 \cdot 9^{\star \star \star}$ & $24 \cdot 3$ & $17 \cdot 5^{\star \star}$ & $26 \cdot 5^{\star \star \star}$ & & $4 \cdot 3^{\star \star \star}$ \\
\hline SES area & & & & & & & & & \\
\hline High (n 447) & $33 \cdot 7$ & $76 \cdot 5$ & $14 \cdot 8$ & $9 \cdot 4$ & $18 \cdot 1$ & $28 \cdot 2$ & $43 \cdot 2$ & & $6 \cdot 4$ \\
\hline Mid ( $n$ 519) & $39 \cdot 1$ & $76 \cdot 1$ & $22 \cdot 5$ & $12 \cdot 7$ & $27 \cdot 6$ & $17 \cdot 0$ & $24 \cdot 1$ & & $1 \cdot 4$ \\
\hline Low $(n 362)$ & $27 \cdot 3$ & $72 \cdot 4$ & $28 \cdot 2^{\star \star \star}$ & $22 \cdot 4^{\star \star \star}$ & $34 \cdot 5$ & $15 \cdot 5^{\star \star \star}$ & $13 \cdot 5^{\star \star \star}$ & & $2 \cdot 1^{\star \star \star}$ \\
\hline
\end{tabular}


Table 2 Multilevel analytical results of socio-economic predictors of meal source

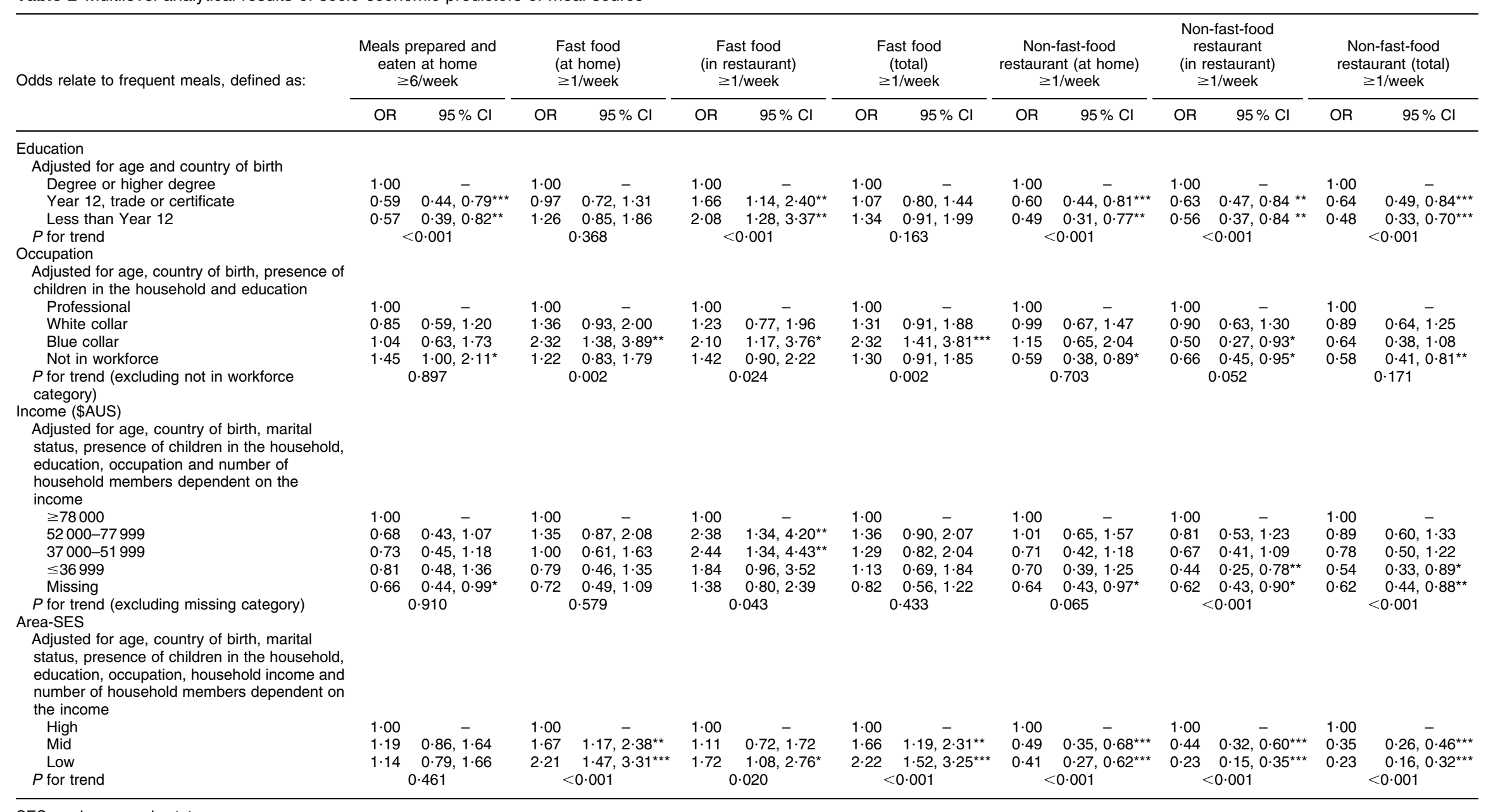

SES, socio-economic status.

$P$ value compared to reference category: ${ }^{*} P<0 \cdot 05,{ }^{* \star} P<0 \cdot 01,{ }^{* * *} P<0.001$. 
non-fast-food restaurants (either eating in a store, at home or total consumption) was less likely among those not in the workforce. Women from the lowest income households were only $44 \%$ as likely as high-income earners to consume a weekly meal within a non-fast-food restaurant and only half as likely to consume non-fast-food restaurant meals, irrespective of the place of consumption. No other significant associations were found for income except among those whose income was categorised as missing. Strong trends were evident for frequent consumption of meals from non-fast-food restaurants, with those in mid- and low-SES neighbourhoods less than half as likely to eat from this source at least once per week after adjustment for individual-level confounders. This held true for total consumption and for the different places of consumption. In fact, the rate of total consumption and consumption within the restaurant was only $23 \%$ as likely among those in low-SES neighbourhoods compared with those in high-SES neighbourhoods.

\section{Discussion}

We analysed socio-economic associations with food prepared and eaten at home, meals from fast-food restaurants and meals from non-fast-food restaurants and also examined the place of consumption for $\mathrm{FPOH}$ sources among women. Owing to the increasing rates of obesity and associated health effects within Australia and other Westernised countries, it is important to better understand the determinants of modifiable behaviours such as eating practices. Our study showed the existence of a number of significant socio-economic associations between individuals and the places where meals were prepared and consumed. Evidence was consistent in suggesting that lower socio-economic characteristics at both the individual and area levels were associated with a higher likelihood of weekly consumption of fast food but lower likelihood of non-fast-food restaurant foods, whereas higher education and not being in the workforce were linked to a greater likelihood of frequent preparation of meals at home. Results also reveal differences by place of consumption, suggesting that other factors such as time pressures may be important.

It is important to consider different socio-economic predictors in dietary research, as each can reveal different mechanisms that contribute to eating behaviours, which has been shown in our results. Specifically, we found lower education to be associated with a greater likelihood of frequently eating meals within a fast-food outlet but with a lower likelihood of frequently preparing and consuming meals at home or from non-fast-food restaurants. Given the less-healthy profile of foods available in fast-food outlets, this association may be driven by a reduced nutritional knowledge $\mathrm{e}^{(23,34)}$ and is of concern given that people with lower nutritional knowledge may make less-healthy choices when purchasing $\mathrm{FPOH}^{(18)}$. It is also likely that many people believe that they are purchasing healthy alternatives when they visit a non-fast-food restaurant rather than a regular fast-food restaurant, which is not necessarily the case ${ }^{(7)}$.

Women who are not in the workforce were more likely to prepare and consume at least six meals at home per week. Given that the time costs for meals must consider all aspects, including preparation, eating and cleaning time ${ }^{(35)}$, this association may be related to a greater amount of time afforded to these women through not having paid work commitments. Alternatively, those who do work may be under more time pressure, which may increase the demand for convenience products such as fast food ${ }^{(24,36-38)}$. Further, blue-collar employees may work non-standard working hours (e.g. shift workers) and this irregular work pattern may be one explanation for their higher consumption of fast food at home. We recognise that time spent in a full-service restaurant may be equivalent to or longer than the total time spent on preparing, cooking and cleaning a meal prepared at home $^{(35)}$. This further highlights the potential differences in factors that may drive the decision to consume at home or within the restaurant. Although we are able to allude to this by exploring whether meals were eaten within the store or at home as takeaway, we were not explicitly able to explore the role of time pressures in our analyses.

Income was also a significant predictor of meal source. Low-income earners may feel entitled to a 'treat' ${ }^{\text {(39) }}$ or meal out, and findings suggest that they are more frequently consuming meals within fast-food outlets, potentially reflecting the lower cost of these as a meal-out alternative ${ }^{(40)}$. Conversely, high-income earners were more likely to consume meals within non-fast-food restaurants on a weekly basis. This decision may reflect the capacity of high-income earners generally to afford these more expensive alternatives, as well as the more favourable service or meal quality, either objectively or perceived. The significant associations with income are consistent with previous evidence showing that cost is the second most important factor in food choice behind taste ${ }^{(41)}$ and that energy-dense foods (such as those found at fast-food restaurants) are generally cheaper and therefore more accessible to low-income consumers ${ }^{(40)}$.

In addition to individual-level predictors, we showed that those living in lower-SES neighbourhoods were more likely to frequently source food from fast-food outlets and less likely to frequently source food from non-fast-food restaurants. In fact, stronger associations in the present study were found when area-SES was modelled as an independent predictor of non-fast-food purchase. It is plausible that some of the effects for fast-food purchasing relate to the food environments in these areas. Those in low-SES neighbourhoods are potentially exposed to more chain brand fast-food outlets ${ }^{(42)}$, with exposure to a greater variety of these outlets having some positive 
associations with purchasing frequency ${ }^{(43)}$. However, it is unknown whether the opposite is true for non-fast-food restaurants.

\section{Strengths and limitations}

Our analysis is strengthened by the inclusion of multiple outcomes related to meal sources (in terms of both place of purchase and place of consumption) and multiple socioeconomic predictors. To our knowledge, this is the first known study to investigate socio-economic associations with multiple sources of meal preparation and consumption, and, by investigating multiple meal sources, the current findings are unique. Although the socio-economic associations with the consumption of takeaway foods have been previously reported in an Australian context ${ }^{(25)}$, the prior study was limited to food consumed at home and they were unable to disentangle associations between fast-food and non-fast-food restaurant purchases, making it difficult to be compared with our findings.

We acknowledge a number of limitations in our analysis. First, it was not possible to account for potentially large variations in the nutritional quality of meals within FPOH categories or meals prepared at home. Second, we were unable to investigate other potentially important determinants of the eating behaviours described (such as time pressures). Third, this sample is restricted to women and only captures their own food-purchasing behaviours precisely. However, in many cases, women are the main purchasers of food for the household, and although we do not suggest that our findings are reflective of meals consumed by all household members, women's eating behaviours are likely to act as an indicator for some of the eating behaviours undertaken by other household members (particularly for main meals). Fourth, we did not assess snack food consumption, nor did we account for the total number of meals eaten per day. Fifth, although we achieved only a modest response rate to our mail-based survey, this is actually similar to that achieved by other mail-based surveys targeting women ${ }^{(44)}$ and is still likely to reflect a broad spectrum of respondents ${ }^{(45)}$. Finally, we acknowledge that by sampling from the lowest, mid and highest septiles of area-level SES we have not captured a population representative sample. However, sampling in this way has allowed us to examine a wider gradient with regard to socio-economic predictors and provided a greater chance of detecting effects ${ }^{(46)}$.

\section{Implications of findings}

There are a number of potential implications of our research findings. Meals prepared at home are potentially healthier than most $\mathrm{FPOH}$ sources; however, external barriers such as time constraints mean it is unlikely that the trend towards increased consumption of $\mathrm{FPOH}$ will be reversed in the near future. Although it has been shown that FPOH does not necessarily have to result in a less-healthy nutritional profile ${ }^{(47)}$, policy makers need to continue campaigns to increase the availability of healthy alternatives in FPOH establishments. Further, at present, it is difficult to know what healthy options are available in FPOH places ${ }^{(48)}$. In terms of promoting greater preparation of meals at home, it could be useful to promote an awareness of the benefits related to the nutritional quality of selected home-prepared meals over both fast-food and full-service restaurant meals. In addition, it may help if parents are aware of the positive effects on children's diets that result from a greater frequency of meals being prepared and eaten at home ${ }^{(49,50)}$. Specifically for lowincome consumers, McDermott and Stephens ${ }^{(51)}$ show that eating out does not need to be seen as a cheaper alternative to food purchased from super markets. They show that through sticking to generic brands and frozen options (e.g. frozen vegetables), it is possible to eat a healthier diet at a cheaper cost than fast food. However, they acknowledge that this is not necessarily appealing to all, and does not consider the costs associated with meal preparation at home, further emphasising the difficulty in eating healthily if an individual is earning a low income.

\section{Conclusions}

Fast food is preferred among women with lower socioeconomic characteristics, whereas non-fast-food restaurant meals were more likely to be frequently consumed among women with higher socio-economic characteristics. Although further research is required to gain a greater understanding of the mechanisms that drive socioeconomic associations with eating behaviours in the broader population, the current results have implications for policy makers who need to continue to campaign to make healthy alternatives available in out-of-home food sources. Perhaps more importantly, there is a need to find ways to encourage people to prepare and eat healthy meals at home.

\section{Acknowledgements}

The present study was funded by the Australian Research Council (DP0665242) and by the National Heart Foundation of Australia (G02 M 0658). Lukar Thornton was supported by a National Health and Medical Research Council Capacity Building Grant, ID 425845. Kylie Ball was supported by a National Health and Medical Research Council Senior Research Fellowship, ID 479513. David Crawford was supported by a VicHealth Research Fellowship. The authors have no conflict of interest to declare. L.E.T. formulated the hypothesis for the present analysis and undertook the statistical analysis; all authors contributed to the interpretation of results and to the writing of the manuscript and approved the manuscript for submission. 


\section{References}

1. Cameron AJ, Welborn TA, Zimmet PZ et al. (2003) Overweight and obesity in Australia: the 1999-2000 Australian Diabetes, Obesity and Lifestyle Study (AusDiab). Med J Aust 178, 427-432.

2. Mokdad AH, Ford ES, Bowman BA et al. (2003) Prevalence of obesity, diabetes, and obesity-related health risk factors, 2001. JAMA 289, 76-79.

3. Must A, Spadano J, Coakley EH et al. (1999) The disease burden associated with overweight and obesity. JAMA 282, 1523-1529.

4. National Health and Medical Research Council (2003) Dietary Guidelines for Australian Adults. Canberra: Australian Government Publishing Service; available at http://www.nhmrc.gov.au/_files_nhmrc/file/publications/ synopses/n33.pdf

5. Pereira MA, Kartashov AI, Ebbeling CB et al. (2005) Fastfood habits, weight gain, and insulin resistance (the CARDIA study): 15-year prospective analysis. Lancet 365, 36-42.

6. Prentice AM \& Jebb SA (2003) Fast foods, energy density and obesity: a possible mechanistic link. Obes Rev $\mathbf{4}$, 187-194.

7. Stewart H, Blisard N, Joliffe D (2006) Let's Eat Out: Americans Weigh Taste, Convenience, and Nutrition. Economic Information Bulletin no. 19. Washington, DC: USDA/ERS.

8. Kant AK \& Graubard BI (2004) Eating out in America, 1987-2000: trends and nutritional correlates. Prev Med 38, 243-249.

9. Guthrie JF, Lin BH \& Frazao E (2002) Role of food prepared away from home in the American diet, 1977-78 versus 1994-96: changes and consequences. J Nutr Educ Behav 34, 140-150.

10. Nicklas TA, Baranowski T, Cullen KW et al. (2001) Eating patterns, dietary quality and obesity. J Am Coll Nutr 20, 599-608.

11. Nielsen SJ, Siega-Riz AM \& Popkin BM (2002) Trends in food locations and sources among adolescents and young adults. Prev Med 35, 107-113.

12. Lin BH, Frazao E, Guthrie JF (1999) Away-From-Home Foods Increasingly Important to Quality of American Diet. Agriculture Information Bulletin no. AIB749. Washington, DC: ERS/USDA.

13. Nielsen SJ, Siega-Riz AM \& Popkin BM (2002) Trends in energy intake in US between 1977 and 1996: similar shifts seen across age groups. Obes Res 10, 370-378.

14. Burns C, Jackson M, Gibbons C et al. (2002) Foods prepared outside the home: association with selected nutrients and body mass index in adult Australians. Public Health Nutr 5, 441-448.

15. Duffey KJ, Gordon-Larsen P, Jacobs DR Jr et al. (2007) Differential associations of fast food and restaurant food consumption with 3-y change in body mass index: the Coronary Artery Risk Development in Young Adults Study. Am J Clin Nutr 85, 201-208.

16. Duffey KJ, Gordon-Larsen P, Steffen LM et al. (2009) Regular consumption from fast food establishments relative to other restaurants is differentially associated with metabolic outcomes in young adults. J Nutr 139, 2113-2118.

17. World Health Organization (2003) Diet, Nutrition, and the Prevention of Chronic Diseases. Joint WHO/FAO Expert Consultation. WHO Technical Report Series no. 916. Geneva: WHO.

18. Beydoun MA, Powell LM \& Wang Y (2009) Reduced awayfrom-home food expenditure and better nutrition knowledge and belief can improve quality of dietary intake among US adults. Public Health Nutr 12, 369-381.

19. Vandevijvere S, Lachat C, Kolsteren P et al. (2009) Eating out of home in Belgium: current situation and policy implications. Br J Nutr 102, 921-928.
20. Orfanos P, Naska A, Trichopoulos D et al. (2007) Eating out of home and its correlates in 10 European countries. The European Prospective Investigation into Cancer and Nutrition (EPIC) study. Public Health Nutr 10, 1515-1525.

21. Turrell G, Bentley R, Thomas LR et al. (2009) A multilevel study of area socio-economic status and food purchasing behaviour. Public Health Nutr 12, 2074-2083.

22. French SA, Harnack L \& Jeffery RW (2000) Fast food restaurant use among women in the Pound of Prevention study: dietary, behavioral and demographic correlates. Int J Obes Rel Metab Disord 24, 1353-1359.

23. Ball K, Crawford D \& Mishra G (2006) Socio-economic inequalities in women's fruit and vegetable intakes: a multilevel study of individual, social and environmental mediators. Public Health Nutr 9, 623-630.

24. Mohr P, Wilson C, Dunn K et al. (2007) Personal and lifestyle characteristics predictive of the consumption of fast foods in Australia. Public Health Nutr 10, 1456-1463.

25. Turrell G \& Giskes K (2008) Socioeconomic disadvantage and the purchase of takeaway food: a multilevel analysis. Appetite 51, 69-81.

26. Thornton LE, Bentley RJ \& Kavanagh AM (2010) Individual and area-level socioeconomic predictors of fast food purchasing. J Epidemiol Community Health (In the Press).

27. Turrell G, Hewitt B, Patterson C et al. (2003) Measuring socio-economic position in dietary research: is choice of socio-economic indicator important? Public Health Nutr $\mathbf{6}$, $191-200$

28. Turrell G \& Kavanagh AM (2006) Socio-economic pathways to diet: modelling the association between socioeconomic position and food purchasing behaviour. Public Health Nutr 9, 375-383.

29. Ball K, Jeffery RW, Crawford DA et al. (2008) Mismatch between perceived and objective measures of physical activity environments. Prev Med 47, 294-298.

30. Ball K, Timperio A \& Crawford D (2009) Neighbourhood socioeconomic inequalities in food access and affordability. Health Place 15, 578-585.

31. Australian Bureau of Statistics (2003) Census of Population and Housing: Socio-Economic Indexes for Areas (SEIFA) ABS Catalogue no. 2033.0.55.001. Canberra: ABS.

32. Walter S \& Tiemeier H (2009) Variable selection: current practice in epidemiological studies. Eur J Epidemiol 24, 733-736.

33. Fleischer NL \& Diez Roux AV (2008) Using directed acyclic graphs to guide analyses of neighbourhood health effects: an introduction. J Epidemiol Community Health 62, 842-846.

34. Parmenter K, Waller J \& Wardle J (2000) Demographic variation in nutrition knowledge in England. Health Educ Res 15, 163-174.

35. Stewart H, Blisard N, Bhuyan S et al. (2004) The Demand for Food Away From Home. Full Service or Fast Food? Agricultural Economic Report no. 829. Washington, DC: ERS/USDA.

36. Manrique J \& Jensen HH (1998) Working women and expenditure on food away-from-home and at-home in Spain. J Agric Econ 49, 321-333.

37. French SA, Story M \& Jeffery RW (2001) Environmental influences on eating and physical activity. Annu Rev Public Health 22, 309-335.

38. Binkley JK (2006) The effects of demographic, economic, and nutrition factors on the frequency of food away from home. J Consum Aff 40, 372-391.

39. Inglis V, Ball K \& Crawford D (2005) Why do women of low socioeconomic status have poorer dietary behaviours than women of higher socioeconomic status? A qualitative exploration. Appetite 45, 334-343.

40. Drewnowski A \& Darmon N (2005) Food choices and diet costs: an economic analysis. J Nutr 135, 900-904. 
41. Glanz K, Basil M, Maibach E et al. (1998) Why Americans eat what they do: taste, nutrition, cost, convenience, and weight control concerns as influences on food consumption. J Am Diet Assoc 98, 1118-1126.

42. Reidpath DD, Burns C, Garrard J et al. (2002) An ecological study of the relationship between social and environmental determinants of obesity. Health Place 8, 141-145.

43. Thornton LE, Bentley RJ \& Kavanagh AM (2009) Fast food purchasing and access to fast food restaurants: a multilevel analysis of VicLANES. Int J Behav Nutr Phys Act 6, 28.

44. Brown WJ, Dobson AJ, Bryson L et al. (1999) Women's Health Australia: on the progress of the main cohort studies. J Womens Health Gend Based Med 8, 681-688.

45. Krosnick JA (1999) Survey research. Annu Rev Psychol 50, 537-567.

46. Blakely TA \& Woodward AJ (2000) Ecological effects in multilevel studies. J Epidemiol Community Health 54, 367-374.
47. You W, Zhang G, Davy BM et al. (2009) Food consumed away from home can be a part of a healthy and affordable diet. J Nutr 139, 1994-1999.

48. Saelens BE, Glanz K, Sallis JF et al. (2007) Nutrition Environment Measures Study in restaurants (NEMS-R): development and evaluation. Am J Prevent Med 32, 273-281.

49. Gillman MW, Rifas-Shiman SL, Frazier AL et al. (2000) Family dinner and diet quality among older children and adolescents. Arch Fam Med 9, 235-240.

50. Neumark-Sztainer D, Hannan PJ, Story M et al. (2003) Family meal patterns: associations with sociodemographic characteristics and improved dietary intake among adolescents. J Am Diet Assoc 103, 317-322.

51. McDermott AJ \& Stephens MB (2010) Cost of eating: whole foods versus convenience foods in a low-income model. Fam Med 42, 280-284. 